\title{
ISOLAMENTO DE BACTÉRIAS COM POTENCIAL PARA PRODUÇÃO DE ANTIMICROBIANOS
}

\author{
C. K. SILVA ${ }^{1}$, A. P. MANERA ${ }^{1}$ e C. C. MORAES ${ }^{1}$ \\ ${ }^{1}$ Universidade Federal do Pampa, Curso de Engenharia de Alimentos \\ E-mail para contato: cleber.klasener@yahoo.com
}

\begin{abstract}
RESUMO - Atualmente a busca da indústria pela conservação de alimentos com aditivos naturais e sintéticos tem motivado pesquisadores. Dessa forma este trabalho visou isolar e selecionar micro-organismos com capacidade de produção de substâncias com potencial antimicrobiano frente à Staphylococcus sp. e E. coli. Para tal, alimentos adquiridos no comércio local foram analisados microbiologicamente e as colônias Gram positivas que apresentaram crescimento em Ágar MRS foram selecionadas. Estes micro-organismos foram cultivados em erlenmeyer contendo caldo MRS Lactobacillus durante 20h. Após, o meio obtido foi então centrifugado, filtrado em membrana de $0,22 \mu \mathrm{m}$ e submetido a testes de inibição contra Staphylococcus sp. e E. coli pelo método de difusão em poços. Os resultados foram analisados e das 36 colônias isoladas, 28 apresentaram ação contra pelo menos um dos micro-organismos testados.
\end{abstract}

\section{INTRODUÇÃO}

Sabe-se que os micro-organismos podem desempenhar papéis muito importantes na indústria de alimentos, e é possível classificá-los em três grupos distintos: os micro-organismos que causam alterações químicas indesejáveis aos alimentos, chamadas de deterioração microbiana; os microorganismos patogênicos, que representam risco à saúde, pois são responsáveis por doenças relacionadas ao consumo de alimentos contaminados com estes organismos ou suas toxinas; e os micro-organismos que causam alterações benéficas nos alimentos (Franco e Landgraf, 2008). Neste ultimo grupo incluem-se os micro-organismos que alteram as características de um determinado produto, transformando em outro produto, como os micro-organismos utilizados para a fabricação de queijos, vinhos, pães, cervejas, e os micro-organismos capazes de produzir compostos de interesse na indústria de alimentos, como enzimas (lipases, amilases, lactases, invertases), corantes (carotenoides, ficocianina), ácidos graxos e bacteriocinas.

$\mathrm{O}$ crescente interesse dos consumidores por alimentos seguros tem incentivado pesquisadores a buscar tecnologias de processamento que atendam a esta demanda (Melo et al., 2005). Segundo dados da Organização Mundial da Saúde (OMS), cerca de $20 \%$ da produção de alimentos é perdida por deterioração, além disso, esses produtos podem servir de veículo para doenças transmitidas por alimentos, conhecidas como DTA, sendo muitas dessas potencialmente fatais (Evangelista, 2000).

Para evitar esses dois problemas a indústria investe em métodos de conservação, tais como 


\section{9 a 22 de outubro de 2014 \\ Florianópolis/SC}

emprego de frio ou calor, uso de radiação ionizante, aplicação de atmosfera modificada, entre outros (Jay, 2005). Em paralelo a essas técnicas pode ser realizada a aplicação de conservantes químicos ou naturais, visando elevar a vida de prateleira dos produtos alimentícios. Esses conservantes são definidos segundo a Portaria no 540 de 27 de outubro de 1997, da Agência Nacional de Vigilância Sanitária (ANVISA) como substâncias que impedem ou retardam a alteração dos alimentos provocada por micro-organismos ou enzimas. Dentre os conservadores naturais encontram-se as bacteriocinas, como a Nisina, Pediocina, Reuterina, que são peptídeos ou proteínas que apresentam atividade antimicrobiana contra uma série de micro-organismos (Drosinos et al., 2008).

Segundo regulamentos da FDA, para que um antimicrobiano natural possa ser usado como conservante de alimentos, este deve ser produzido por micro-organismos GRAS. Como muitas espécies de bactérias lácticas apresentam o status GRAS, elas têm sido extensamente estudadas para a produção de bacteriocinas. O FDA e o FSIS do Departamento de Agricultura dos Estados Unidos confirmam a segurança, a eficiência e o uso de novos conservantes, incluindo as bacteriocinas (Post, 1996).

Bacteriocinas são proteínas ribossomicamente sintetizadas, produzidas na fase lag de multiplicação microbiana, que não apresentam até o momento aplicação clínica e não alteram a microbiota do trato gastrointestinal, pois estas são digeridas por enzimas como tripsina e pepsina encontradas no sistema digestivo. Diferentes dos antibióticos que são metabólitos secundários sintetizados por enzimas e apresentam aplicação clínica. Se as bacteriocinas fossem consideradas antibióticos, não poderiam ser utilizadas em alimentos, já que o uso de antibióticos em alimentos é ilegal (Drosinos, et al., 2008; Rosa, et al., 2002; Lee, et al., 2013).

Algumas das bacteriocinas mais conhecidas e estudadas até o momento são a Pediocina, Reuterina e a Nisina. Esta ultima é um peptídeo antimicrobiano produzido por cepas de Lactococcus lactis, aprovada pelo FDA para utilização em alimentos como agente de conservação natural e pela ANVISA para a conservação de queijos, apresenta um grande espectro bactericida contra bactérias Gram-positivas (Machado, Borges, Bruno, 2011).

Apesar de ainda serem pouco utilizadas em alimentos, as bacteriocinas apresentam grande potencial para utilização como conservante complementar, para tanto se faz necessário o estudo cada vez mais aprofundado da ação das bacteriocinas já estudadas, além é claro do isolamento de bactérias que apresentem ação antimicrobiana sobre micro-organismos deterioradores e patogênicos. Dessa forma este trabalho visou isolar e selecionar micro-organismos com capacidade de produção de substâncias com potencial antimicrobiano frente à Staphylococcus sp. e E. coli.

\section{METODOLOGIA}

\subsection{Isolamento das colônias}

Os micro-organismos foram isolados de diferentes alimentos: salsicha, presunto, salame 


\section{9 a 22 de outubro de 2014 \\ Florianópolis/SC}

italiano, linguiça calabresa embalada vácuo e três tipos de iogurtes ditos funcionais. Os alimentos foram adquiridos no mercado local e transportados em caixas térmica contendo gelo até o Laboratório de Microbiologia e Toxicologia de Alimentos da UNIPAMPA, Campus Bagé.

Uma amostra de 25 gramas do alimento mais $225 \mathrm{~mL}$ de água peptonada foram homogeneizados com auxilio de homogeneizador de amostras tipo Stomacher e um $\mathrm{mL}$ desta mistura foi colocado em placa de Petri seguida da adição de ágar MRS Lactobacilli. As placas foram incubadas a $32^{\circ} \mathrm{C}$ por $48 \mathrm{~h}$ em condições de microaerofilia, obtida com o auxilio de jarras de anaerobiose e gerador anaerobac. Ao final desse período as placas contendo colônias características de bactérias ácido-láticas (BAL), brancas e pequenas, que ao serem submetidas a testes de coloração de Gram e microscopia, apresentaram-se Gram +, foram colocadas em tubos de ensaio contendo ágar MRS, incubadas nas mesmas condições do isolamento, $32^{\circ} \mathrm{C}$ por $48 \mathrm{~h}$, armazenadas sob refrigeração $\left(4^{\circ} \mathrm{C}\right)$ até os testes de produção de bacteriocinas.

\subsection{Cultivo e obtenção do extrato livre de células}

Para o cultivo dos micro-organismos isolados na etapa anterior, foram utilizados erlenmeyer de $250 \mathrm{~mL}$ contendo $100 \mathrm{~mL}$ de meio de cultura MRS modificado segundo Costa et al (2011), a este foi inoculado o isolado na proporção de $1: 10(\mathrm{v} / \mathrm{v})$ e incubado a $32^{\circ} \mathrm{C}$ por $20 \mathrm{~h}$ sob agitação de $150 \mathrm{rpm}$. Após incubação, realizou-se a separação das células por centrifugação a $2100 x g$ por 15 min a $4^{\circ} \mathrm{C}$, o sobrenadante foi submetido à filtração em membrana de $0,22 \mu \mathrm{m}$ com auxilio de bomba a vácuo. Ao filtrado atribuiu-se o nome de filtrado livre de células.

Para verificar o tempo de produção do agente antimicrobiano (bacteriocina) foi realizada cinética de produção em 96 h, para isso utilizou-se o micro-organismo isolado PEO05, este foi inoculado e incubado nas condições de estudo e uma amostra de $10 \mathrm{~mL}$ foi retirada a cada $24 \mathrm{~h}$, esta amostra foi centrifugada, filtrada e submetida ao teste de inibição.

\subsection{Determinação da atividade antimicrobiana}

Os filtrados livre de células foram submetidos ao teste de difusão em poços para detecção da capacidade de inibir Staphylococcus sp e E. coli. Para isso seguiu-se a metodologia descrita por Lewus e Montville (1991) com adaptações.O filtrado livre de células teve o pH ajustado para 7,0 utilizando-se solução de $\mathrm{NaOH} 10 \mathrm{~N}$, para evitar uma possível atividade inibitória decorrente da produção de ácidos orgânicos. Transferiu-se $20 \mu \mathrm{L}$ para poços de $4 \mathrm{~mm}$, feitos em placas contendo ágar Müller Hinton previamente contaminado com aproximadamente $10^{6} \mathrm{UFC} / \mathrm{mL}$ de Staphylococcus sp. e também contra Escherichia coli. As placas foram incubadas a $37^{\circ} \mathrm{C}$ por um período de $24 \mathrm{~h}$. A formação de um halo de inibição da multiplicação bacteriana no local onde o sobrenadante foi colocado, indicou a atividade antimicrobiana. 


\section{RESULTADOS E DISCUSSÕES}

As colônias isoladas e devidamente codificadas são apresentadas na Tabela 1. Estas quando submetidas à microscopia e coloração de Gram apresentaram-se em sua totalidade como Gram +, sendo 25 na forma de bastonete e 11 na forma de cocos.

Tabela 1 - Caracterização e capacidade de produção dos isolados

\begin{tabular}{|c|c|c|c|c|}
\hline \multirow{2}{*}{$\begin{array}{c}\text { Código } \\
\text { Amostra }\end{array}$} & \multicolumn{2}{|c|}{ Caracterização } & \multicolumn{2}{|c|}{ Ação antimicrobiana } \\
\hline & Gram & Morfologia & E. coli & Staphylococcus sp. \\
\hline SLE01 & + & Bastonete & + & + \\
\hline SLE02 & + & Bastonete & - & - \\
\hline SLE03 & + & Bastonete & + & + \\
\hline SLE04 & + & Bastonete & + & + \\
\hline SLE05 & + & Bastonete & + & + \\
\hline SLE06 & + & Bastonete & + & + \\
\hline SLE07 & + & Bastonete & + & + \\
\hline SLE08 & + & Bastonete & + & + \\
\hline PEO01 & + & Bastonete & + & - \\
\hline PEO02 & + & Bastonete & - & - \\
\hline PEO03 & + & Bastonete & - & - \\
\hline PEO04 & + & Bastonete & - & - \\
\hline PEO05 & + & Bastonete & + & + \\
\hline PEO06 & + & Bastonete & - & - \\
\hline CLA01 & + & Bastonete & + & - \\
\hline CLA02 & + & Bastonete & + & - \\
\hline CLA03 & + & Bastonete & - & - \\
\hline CLA04 & + & Cocos & + & - \\
\hline CLA05 & + & Bastonete & - & - \\
\hline CLA06 & + & Bastonete & - & - \\
\hline CLA07 & + & Bastonete & + & - \\
\hline SLA01 & + & Cocos & + & - \\
\hline SLA02 & + & Cocos & + & - \\
\hline SLA03 & + & Bastonete & + & - \\
\hline SLA04 & + & Cocos & + & - \\
\hline SLA05 & + & Cocos & + & - \\
\hline SLA06 & + & Bastonete & + & - \\
\hline IAA01 & + & Cocos & + & - \\
\hline IAA02 & + & Cocos & + & - \\
\hline IAA03 & + & Cocos & + & - \\
\hline IPE01 & + & Bastonete & + & - \\
\hline IPE02 & + & Bastonete & + & - \\
\hline IPE03 & + & Bastonete & + & - \\
\hline IAE01 & + & Cocos & + & - \\
\hline IAE02 & + & Cocos & + & - \\
\hline IAE03 & + & Cocos & + & - \\
\hline
\end{tabular}

Os resultados obtidos durante o acompanhamento da produção das bacteriocinas podem ser observados na Figura 1 onde é possível perceber a formação de halos de inibição por PEO 05 frente a 
E. coli, ainda percebe-se que a produção ocorre nas primeiras $24 \mathrm{~h}$ de cultivo. Do ponto de vista econômico esse resultado é considerado interessante, já que os custos de produção se tornam mais baixos quando o tempo de cultivo é menor.

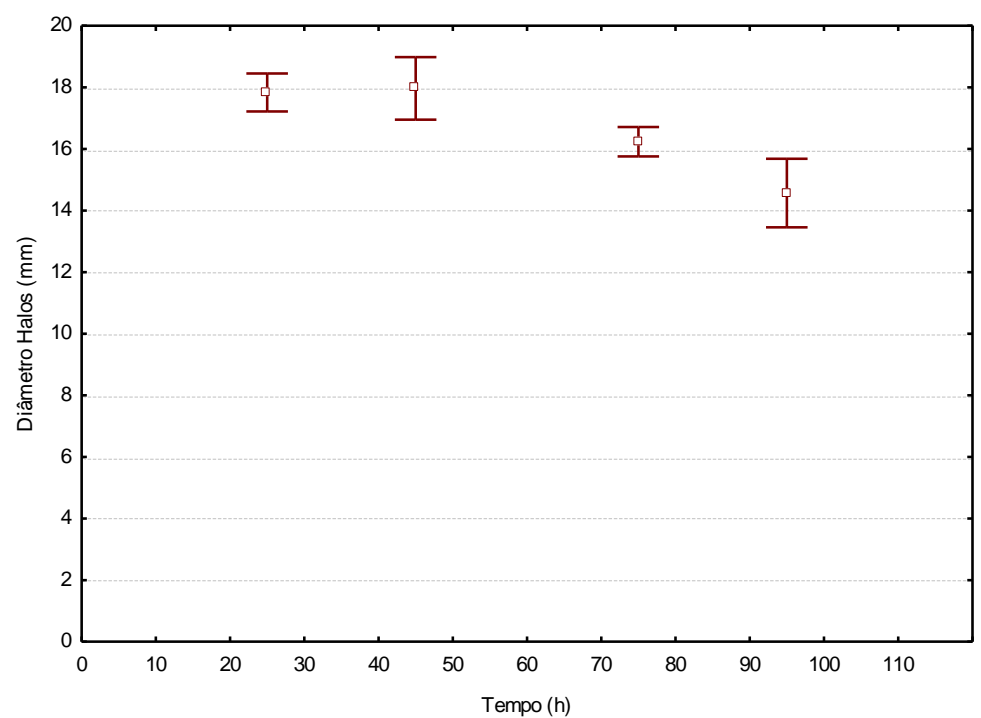

Figura 1 - Estudo do tempo de produção do agente antimicrobiano.

Trabalhos como os de Naclerio et al. (1993) e Paik et al. (1997) apontam que no tempo de 18-20 $\mathrm{h}$ de cultivo, ocorre a maior produção de agentes antagônicos por bactérias láticas, tempo este correspondente ao período de colonização do meio e inicio da fase estacionária de multiplicação celular.

Quanto a produção dos agentes antimicrobianos, pode-se observar também através da Tabela 1, que das 36 colônias inicialmente isoladas, 28 apresentaram a formação de halos de inibição contra pelo menos um dos micro-organismos testados. Ainda na Tabela 1 observa-se a ação do agente antimicrobiano sobre os dois micro-organismos testados, contra Staphylococcus sp. os isolados SLE01, 03, 04, 05, 06, 07 e 08, além do isolado PEO05 apresentaram atividade antimicrobiana, visualizada pela formação de pequenos halos transparentes ao redor dos poços, Figura 2.a. Já contra E. coli apenas os isolados SLE02, PEO02, PEO03, PEO04, PEO06, CLA03, CLA05 e CLA06 não apresentaram halos de inibição. 
(a)

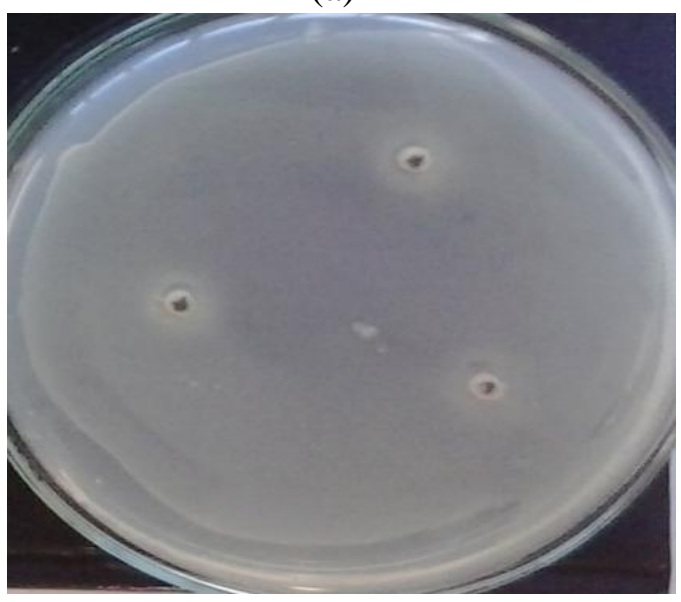

(b)

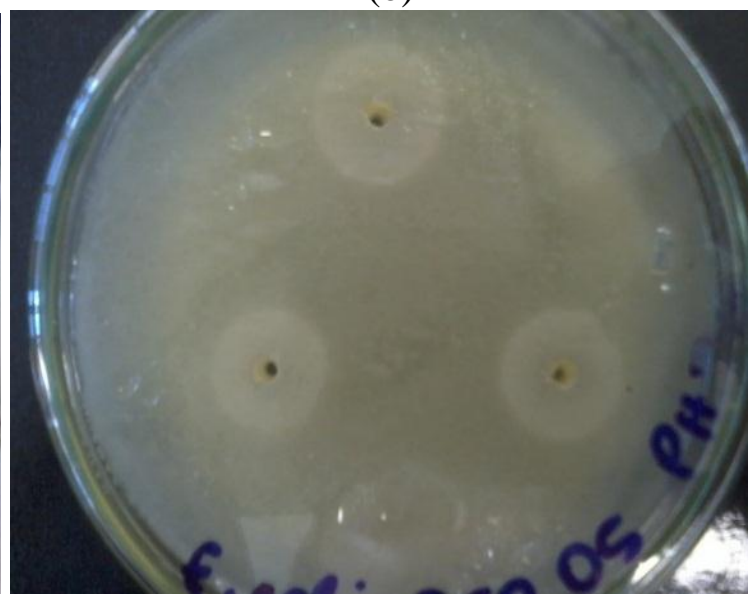

Figura 2 - Halos de inibição conta (a) Staphylococcus sp e (b) E.coli

Nos halos formados contra E. coli, Figura 2.b, percebeu-se que inicialmente ocorrera a formação de halos transparentes e característicos, porém com o passar do tempo verificou-se que o micro-organismo contaminante tomara conta da placa como um todo, isso provavelmente ocorreu porque a concentração de bacteriocinas não era tão alta ao ponto de ser suficiente para inibir o microorganismo contaminante durante as $24 \mathrm{~h}$ de incubação. Uma teoria para ação mais efetiva do composto gente a $E$. coli é que como o isolado produtor é Gram positivo, este poderia produzir agentes antimicrobianos com ação contra bactérias Gram negativas, já que as paredes celulares são diferentes, evitando assim que a bacteriocina produzida tenha ação conta a própria produtora.

\section{CONCLUSÕES}

Ao final desse trabalho foram isoladas 28 micro-organismos que apresentaram ação antimicrobiana principalmente sobre $E$. coli, caso este que deve ser investigado mais a fundo, já que normalmente as bactérias láticas produzem compostos com ação sobre micro-organismos Gram positivos e apenas algumas apresentam ação contra Gram negativos. Entre os estudos que devem ser realizados para melhor compreender estes agentes antimicrobianos estão identificar os microorganismos produtores e o agente antimicrobiano produzido.

Verificou-se também que a produção do agente antimicrobiano ocorrera nas primeiras $24 \mathrm{~h}$ de cultivo, tempo este que se equipara a dados obtidos em trabalhos similares encontrados na literatura.

\section{REFERÊNCIAS}

BRASIL. ANVISA. Agencia Nacional de Vigilância Sanitária. Portaria nº540 de 27 de outubro 
de 1997. P.4.

COSTA, A. L. P., et al. Avaliação de Modificações no Meio MRS (Seletivo para Lactobacillus spp) por Diferentes Sais de Amônia e Tween 20 em Substituição ao Citrato de Amônio e Tween 80. Ciência Equatorial, v. 1, n. 2, 2011.

DROSINOS, E. H.; MATARAGAS, M. P. Antimicrobial Activity of Bacteriocins and Their Applications. Meat Biotechnology. New York: Editora Fidel Todldrá, 2008.

EVANGELISTA, J. Tecnologia de Alimentos. São Paulo, Editora Atheneu, $2^{\mathrm{a}}$ edição, 2000.

FRANCO, D. G. M. B.; LANDGRAF, M. Microbiologia de Alimentos. São Paulo: Editora Atheneu, 2008.

JAY, M, JAMES. Microbiologia de Alimentos. Porto Alegre: Editora Artmed, 2005.

LEE, N. K. et al. Antimicrobial Effect of Bacteriocin KU24 Produced by Lactococcus lactis KU24 against Methicillin-Resistant Staphylococcus aureus. Journal of Food Science, v. 78: p. 465469, 2013.

LEWUS, C.B.; MONTVILLE, T.J. Detection of bacteriocins produced by lactic acid bacteria. Journal of Microbiology Methods, v.13, p.145-150, 1991.

MACHADO, T. F.; BORGES, M. F.; BRUNO, L. M.; Aplicação de Antimicrobianos da Conservação de Alimentos. Fortaleza: EMBRAPA, doc 145, 2011.

MELO, R. N.; SOARES, F. F. N.; GONÇALVES, C. J. P. M. Nisina: um conservante natural para alimentos. Ceres, v. 52, n.303, p. 921-938, 2005.

NACLERIO, G. et al. Antimicrobial activity of a newly identified bacteriocina of Bacillus cereus. Appied. Envirion Microbiol. v. 59, 4314-4316, 1993.

PAIK, H. D.; BAE,S. S. e PAN, J. G. Identification and partial characterization of tochicin, a bacteriocina produced by Bacillus thuringiensis subsp. Tochigiensis. Journal of Industrial Microbiology and Biotechnology. v. 19, p, 294-298, 1997.

POST, C.; Regulatory perspective of USDA on the use of antimicrobial and inhibitors in food. Journal of food protection, p 78 - 81, 1996.

ROSA, M. C.; FRANCO, M. D. G. M. Bacteriocinas de Bactérias Lácticas. ConSCIENTIAE SAÚDE, v 1, 2002. 